\title{
Argon Excluder Foam Compression Data
}

Douglas Clark

7/25/91

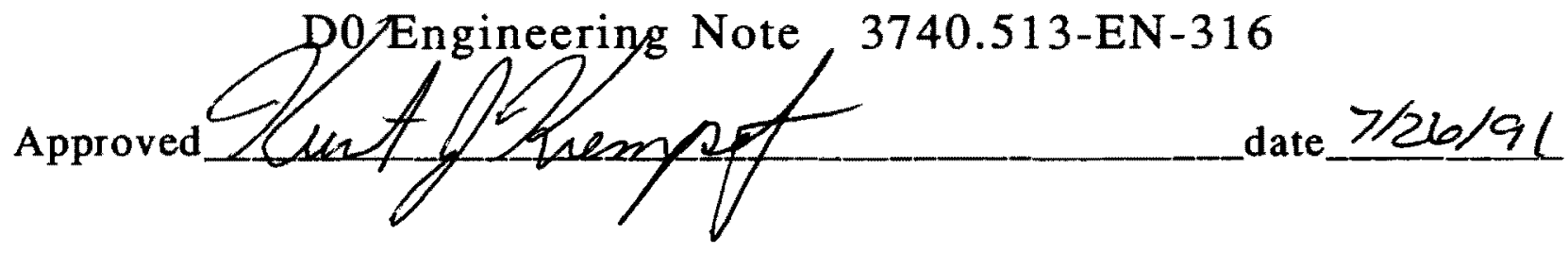




\section{INTRODUCTION}

The argon excluder is designed to reduce the media density of the dead space between the internal modules of the end calorimeters and the concave convex head to less than that of argon. The design of the excluder includes a thin circular stainless steel plate welded to the inner side of the convex pressure vessel head at a radius of $2615 / 16$ inches. It is estimated that this plate will experience a pressure differential of approximately 40 pounds per square inch. A inner foam core is incorporated into the design of the excluder as structural support. This engineering note outlines the compression data for the foam used in the north end calorimeter argon excluder.

\section{MATERIAL SPECIFICATIONS}

Stephanfoam foam system BX $345 \mathrm{~N}$

Nominal density: $11 \mathrm{lbs} / \mathrm{ft}^{3}$

Manufacturer: Stephan Company, Northfield, Il. 60093

\section{TEST PROCEDURE}

Four test samples of approximately the same dimensions were cut and machined from large blocks of the poured foam. Two of these test samples were then subjected to varying compression magnitudes until failure. For this test failure was taken to mean plastic yielding or the point at which deformation increases without a corresponding increase in loading. The third sample was subjected to a constant compressive stress for an extended period of time, to identify any "creeping" effects. Finally, the fourth sample was cooled to cryogenic temperatures in order to determine the coefficient of thermal expansion.

The compression test apparatus consisted of a state of the art INSTROM coupled with a PC workstation. The tests were run at a constant strain rate with discrete data taken at 500 millisecond intervals. The sample data is plotted as a stress strain diagram in the results.

The first test was run on sample number one at a compression rate of $0.833 \mathrm{mil} / \mathrm{s}$ or equivalently a strain rate of $3.245 \times 10^{\wedge}-4 \mathrm{mil} / \mathrm{mil} / \mathrm{s}$. The corresponding stress was then calculated from the force measured divided by the given initial area. The test was run for thirty minutes until the mode of failure, plastic yielding, was reached. The second test was run as 
EN-316

a check of the first using sample number two, and likewise was conducted in the same manner. However, the strain rate for the second test was increased to $6.66 \times 10^{\wedge}-4 \mathrm{mil} / \mathrm{mil} / \mathrm{s}$ which reduced the test time to fifteen minutes.

The third sample was subjected to a compressive stress of forty pounds per sqaure inch, the estimated MAWP, for a period of thirty minutes. Data was taken manually by the operator and an estimate is provided in the results.

The thermal test conducted on sample number four consisted of cooling the sample to $77 \mathrm{~K}$ using an open mouth dewar filled with liquid nitrogen. The sample was then measured (all dimensions) warm, 298K, and cold, $77 \mathrm{k}$, and the measurements compared. The sample was then allowed to warm and the test was repeated. The calculation of the coefficient of thermal expansion is provided in the results.

\section{RESULTS}

The samples were weighed and measured prior to conducting any tests. The density is calculated here:

$\begin{array}{llllllll}\begin{array}{l}\text { Sample } \\ \text { Number }\end{array} & \begin{array}{l}\text { Height } \\ \text { in. }\end{array} & \begin{array}{l}\text { Length } \\ \text { in. }\end{array} & \begin{array}{l}\text { width } \\ \text { in. }\end{array} & \begin{array}{l}\text { Area } \\ \text { in^2 }\end{array} & \begin{array}{l}\text { Volume } \\ \text { in^3 }\end{array} & \begin{array}{l}\text { Mass } \\ \text { lbs }\end{array} & \begin{array}{l}\text { Density } \\ \text { lbs/ft^3 }\end{array} \\ 1 & 2.567 & 3.038 & 3.206 & 9.74 & 25.002 & 0.1517 & 10.49 \\ 2 & 2.507 & 3.005 & 3.288 & 9.88 & 24.77 & 0.15 & 10.47 \\ 3 & 2.563 & 3.268 & 2.969 & 9.703 & 24.868 & \text { NA } & \text { NA } \\ 4 & 2.621 & 3.241 & 2.979 & 9.655 & 25.306 & \text { NA } & \text { NA }\end{array}$

NA - Not Available

TEST \#1-

A plot of the data is contained on the following pages entitled Argon Excluder Foam/Compression Data-Test 1.

TEST \#2-

A plot of the data is contained on the following pages entitled Argon Excluder Foam/Compression data-Test 2.

Test \#3-

The third sample when subjected to a compressive load of $40 \mathrm{psi}$ for a period of thirty minutes compressed to $2.55 \mathrm{in}$ or an equivalent strain 
EN-316

of 0.0051 . The sample then held steady over the duration of the test, changing $0.0006 \mathrm{in}$. over thirty minutes. When unloaded, the sample returned to its original length.

\section{TEST \#4-}

are as follows:

The results of the fourth sample subjected to thermal stresses

SAMPLE

NUMBER

4-height

WARM

4-length

2.621

3.241

4-width

2.979

COLD
2.605
3.220
2.957

DIMENSION

WARM

2.619

COLD

WARM

2.603

2.619

3.238

3.218

3.239

2.977

2.960

2.978

The coefficient of thermal expansion is then calculated to be:

$\alpha$-coefficient of thermal expansion

$\delta 1$ - average change in dimension length

$\mathrm{L}$ - original dimension length

$\Delta \mathrm{T}$ - Absolute temperature change

$$
\alpha=\delta 1 /\left(L^{*} \Delta \mathrm{T}\right)=2.81 \times 10^{\wedge}-5 / \mathrm{K}
$$

This coefficient of thermal expansion will result in a contraction of 6 mils per inch if the foam is cooled from room temperature to liquid nitrogen temperature, $77 \mathrm{~K}$.

\section{CONCLUSION}

The argon excluder is expected to see a maximum pressure differential of $40 \mathrm{psi}$, which is a combination of the operating pressure, liquid head, and atmospheric pressure. This pressure is well within the allowable limits of the foam whose yield stress has been shown to be 295 psi. This provides a saftey factor of approximately 7 . In addition the thermal contraction of the structural foam has been shown to be larger than stainless steel only by a factor of two. Thus, the foam will adequately support the load experienced by the thin cover plate of the argon excluder. 


\section{Argon Excluder Foam Compression Data - Test 1}

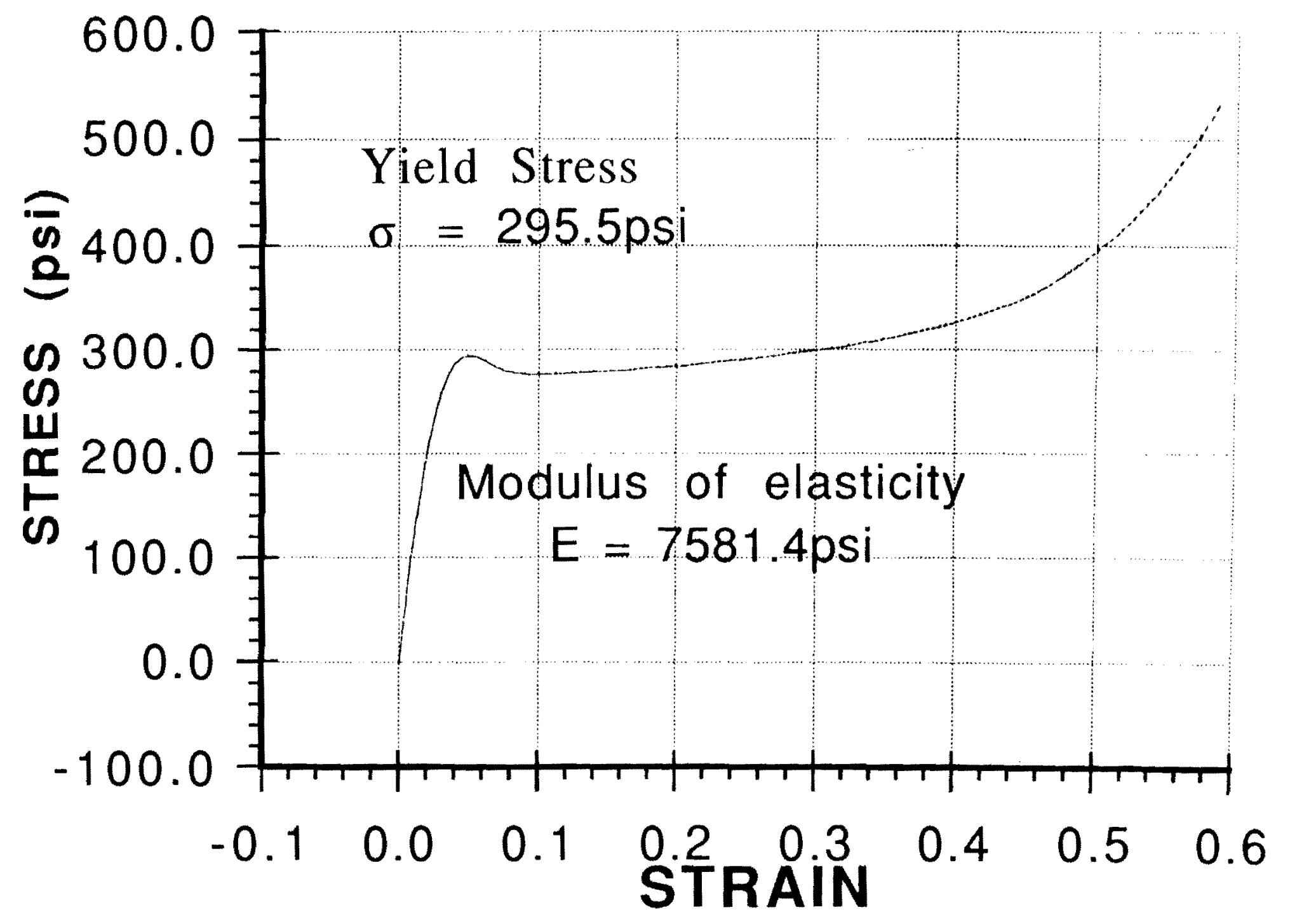




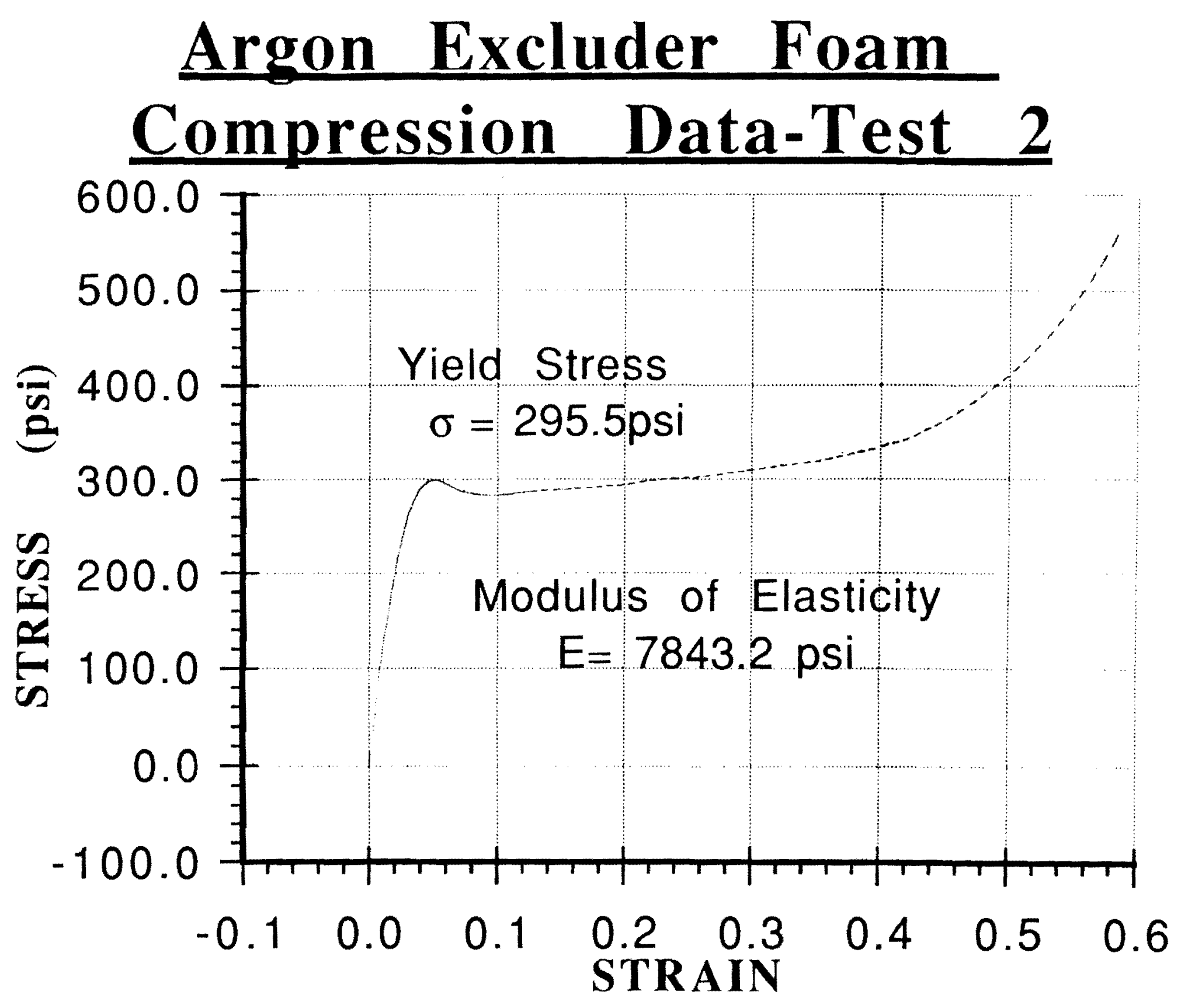

